\title{
Hypoplastic right heart complex in a 46-year-old woman
}

\author{
McDonald K. Horne, III and David T. Rowlands, $\mathrm{Jr}^{1}$ \\ From the Department of Pathology, Duke University Medical Center, Durham, \\ North Carolina 27706, U.S.A.
}

The case is reported of a 46-year-old woman with congenital right ventricular hypoplasia, severe tricuspid stenosis, pulmonary hypoplasia, and an intact ventricular septum. This cardiac malformation is extremely rare in adults. Pulmonary circulation was augmented by bronchial collaterals.

The recently designated 'hypoplastic right heart complex' (Khoury et al., I969), consisting of various degrees of right ventricular hypoplasia, congenital tricuspid stenosis, and pulmonary stenosis, is extremely rare beyond childhood (Sackner et al., I96r; Williams, Barratt-Boyes, and Lowe, 1963). This report is of a woman who survived 46 years with this complex.

\section{Case report}

The patient had been cyariotic since birth. She was first evaluated at Duke University Medical Center when she was 20 years old at which time her heart was slightly enlarged but no murmurs were heard. At the age of 24 she developed pelvic thrombophlebitis which resulted in paradoxical emboli and an acute diaphragmatic myocardial infarction. Shortly thereafter she began to have occasional chest pain, but she did not require cardiac medication.

Deterioration of cardiac function, in fact, did not begin until six months before death when the chest pain became more frequent and signs of congestive heart failure appeared. A phonocardiogram one month before death disclosed an apical systolic murmur, a widely split second heart sound which moved slightly with respiration, and an early pulmonary ejection murmur.

Three weeks later the patient was admitted to hospital with congestive heart failure. Her blood pressure was $140 / 80 \mathrm{~mm}$. $\mathrm{Hg}$, and her pulse was irregular at 130 a minute. She was cyanotic with clubbing of her fingers and toes. The point of maximum cardiac impulse was diffuse in the sixth intercostal space at the anterior axillary line. A grade $3 / 6$ blowing, mid-systolic murmur radiated from the apex to the left axilla. There was fixed splitting of the second sound along the left

1 Correspondence should be addressed to Dr. David T. Rowlands, Jr., Department of Pathology, School of Medicine, University of Pennsylvania, Philadelphia, Penn., 19104, U.S.A. sternal border. No gallops were heard. Her haematocrit was 56 per cent.

An electrocardiogram indicated right axis deviation, biatrial enlargement, premature ventricular contractions, poor $\mathbf{R}$ wave progression, $Q$ waves in leads II, III, and aVF, and $T$ wave inversion in leads II, III, aVF, V5, and V6. Radiological examination of the heart showed left ventricular and biatrial enlargement. The pulmonary vasculature was diminished. There was evidence, however, of prominent bronchial circulation.

Cardiac catheterization revealed bidirectional shunting across a large atrial septal defect. Mean pressures in the right and left atria were 20 and 21 $\mathrm{mm} . \mathrm{Hg}$, respectively, with a left ventricular pressure of I I / /4-22 mm. Hg. The catheter could not be passed through the tricuspid valve. Oxygen saturation was 56 per cent in the inferior vena cava, 70 per cent in the right atrium, 79 per cent in the left atrium, 77 per cent in the left ventricle, and 80 per cent in the aortic root.

Angiocardiography showed sequential opacification of the right atrium, left atrium, left ventricle, and the aorta. The right ventricle and a small pulmonary artery could be detected only on the last films of left ventriculography.

After injection of the contrast material the patient suddenly became unresponsive and more cyanotic. Three days later she died in ventricular fibrillation.

Necropsy findings The heart weighed $480 \mathrm{~g}$. The great vessels arose normally, but the pulmonary artery was small and the aorta was dilated. An atrial septal defect, $2 \mathrm{~cm}$. in diameter, was present. The ring of the tricuspid valve was hypoplastic, $6.9 \mathrm{~cm}$. in circumference (Fig.). The valvular cusps had apparently never separated, so that a single circumferential leaf was present, leaving a stenotic orifice $I \mathrm{~cm}$. in diameter. The right ventricle was small. Though the pulmonary valve was hypoplastic with a ring circumference of $4.1 \mathrm{~cm}$., the valve leaflets appeared normal 


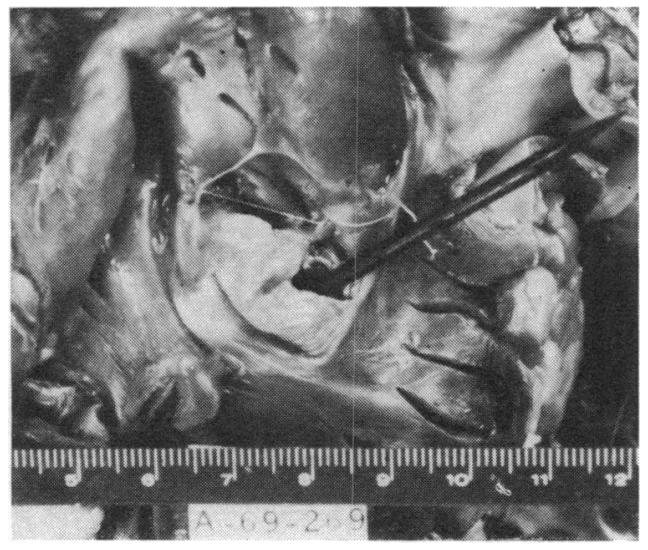

FI G. Gross photograph of tricuspid valve and right ventricle. The probe is positioned through the stenotic valve. A portion of the hypoplastic pulmonary valve is seen at the upper right.

except for their small size. The left atrium and left ventricle were dilated but otherwise normal. The mitral ring was dilated and the valve appeared insufficient. In the diaphragmatic myocardium there was a large, healed infarction which probably permitted aneurysmal dilatation during life. However, the coronary arteries were widely patent showing little atherosclerosis.

There were no significant lesions of the pulmonary blood vessels, and the ostia of the bronchial arteries were not enlarged. The left middle cerebral artery was occluded by an embolus, causing infarction of the left temporal lobe.

\section{Discussion}

Prolonged survival with severe malformations of the right heart requires an alternate route for pulmonary blood flow. Interatrial shunts are uniformly found in these patients. Tricuspid atresia or severe tricuspid stenosis in adults ordinarily necessitates a ventricular septal defect and enough pulmonary outflow obstruction to prevent hypertension (Castleman and McNeely, 1969; Jordan and Sanders, 1966). However, we could find two case reports of right ventricular hypoplasia coupled with stenosis or hypoplasia of the tricuspid valve without interventricular communication. One patient was a 23-year-old man (Sackner et al., 1961), the other a 39-year-old man (Popper, Kushner, and Gasul, 1956). Similarly, the patient we are describing had no ventricular septal defect. Apparently the severe obstruction to pulmonary blood flow was largely overcome in this case through collateral bronchial circulation. Though evidence of these collaterals was not found at necropsy, they were shown by $x$-ray examination.

This patient's long survival was especially remarkable because her myocardium had been weakened 22 years before death by a large diaphragmatic infarction.

\section{References}

Castleman, B., and McNeely, B. U. (1969). Case records of the Massachusetts General Hospital. Weekly clinicopathological exercises. Case 6-1969 New England fournal of Medicine, 280, 317.

Jordan, J. C., and Sanders, C. A. (1966). Tricuspid atresia with prolonged survival. A report of two cases with a review of the world literature. American fournal of Cardiology, 18, I12.

Khoury, G. H., Gilbert, E. F., Chang, C. H., and Schmidt, R. (1969). The hypoplastic right heart complex. American fournal of Cardiology, 23, 792.

Popper, H., Kushner, D. S., and Gasul, B. (1956). Adult fibroelastosis with congenital tricuspid stenosis. Circulation, 14, 412.

Sackner, M. A., Robinson, M. J., Jamison, W. L., and Lewis, D. H. (196I). Isolated right ventricular hypoplasia with atrial septal defect or patent foramen ovale. Circulation, 24, 1388.

Williams, J. C. P., Barratt-Boyes, B. G., and Lowe, J. B. (1963). Underdeveloped right ventricle and pulmonary stenosis. American fournal of Cardiology, II, 458 .

\begin{abstract}
Notice
The 'Fondation de Physiopathologie Professeur Lucien Dautrebande' will award during the year 1973 an international prize of about 500,000 Belgian Francs (\$10,000 U.S.).

It will be a reward for work on human or animal physiopathology, such work preferably having therapeutic implications. For further information about this prize, please write to the office of the Foundation: 35, chaussée de Liège, 5200 Huy (Belgium).
\end{abstract}

